\title{
Selection of the Electrical Generator for a Wave Energy Converter
}

\author{
J. L. Osa Amilibia ${ }^{1}$ and A. Iturregi Aio ${ }^{2}$ \\ ${ }^{1}$ Mechanical Engineering Department, \\ University College of Technical Engineering, University of the Basque Country, \\ La Casilla Plaza 3, 48012 Bilbao, Spain \\ Phone: +34 634 409561, Fax: +34 94601 7800, e-mail: j.osa@ehu.es \\ ${ }^{2}$ Department of Electrical Engineering, \\ University College of Technical Mining and Civil Engineering, University of the Basque Country, \\ Colina Beurko s/n, 48901 Barakaldo, Spain \\ Phone: +34 94601 4979, Fax: +34 94601 7800, e-mail: araitz.iturregi@ehu.es
}

\begin{abstract}
This paper presents the study accomplished to select the electrical generator implemented on a new design of Wave Energy Converter (WEC), identifying the key features that must be taken into account when studying the feasibility of a power plant for a given location and rated power. After introduced the proposed WEC, a review of different solutions adopted by other WEC system is presented. After an introduction of synchronous and asynchronous generator families, their means of working with variable speed and their capability to work connected to grid or isolated is explained. Both of them can work with variable speed, therefore the influence of selected generator in the control strategy and the efficiency gain working with variable speed is studied. The cost of the generation system and the investment return of the facility play an active role when selecting the generator system. After discussed their characteristics advantages and influence in the efficiency, some references will be given to take into account in the design procedures to define a WEC system for a given location.
\end{abstract}

\section{Key words}

Wave energy converter, generator selection, synchronous permanent magnet generator (PMG), asynchronous induction generator (DFIG)

\section{Nomenclature}

$\mathrm{H}_{\mathrm{S}}(\mathrm{m})$ - Significant wave height $\mathrm{T}(\mathrm{s})$ - Period

$\mathrm{N}_{\text {OPT }}(\mathrm{rpm})$ - Optimal speed $\quad \mathrm{D}_{\mathrm{T}}(\mathrm{m})$ - Turbine diameter

$\mathrm{u}(\mathrm{m} / \mathrm{s})$ - Buckets linear speed $\mathrm{v}_{\mathrm{J}}(\mathrm{m} / \mathrm{s})$ - Water speed in the jet

$\mathrm{Q}\left(\mathrm{m}^{3} / \mathrm{s}\right)$ - Turbine discharge $\mathrm{P}(\mathrm{kW})$ - Power output

$\mathrm{D}_{\mathrm{C}}(\mathrm{m})$ - Cylinder diameter $\quad \mathrm{c}(\mathrm{m})$ - Cylinder stroke

E (J) - Energy

L (J) - Energy loss

$\mathrm{hf}(\mathrm{m})$ - Pressure drop

$\mathrm{g}(\mathrm{m} / \mathrm{s} 2)$ - Gravity

$\gamma(\mathrm{N} / \mathrm{m} 3)-$ Specific weight

$\mathrm{p}-\mathrm{N}$. of poles

occ $-\mathrm{N}$. of occurrences

$\mathrm{h}_{\mathrm{N}}(\mathrm{mca})-$ Net height

$\rho(\mathrm{kg} / \mathrm{m} 3)-$ Sea water density

$\eta$ - Efficiency

WEC - Wave Energy Converter

PM - Permanent Magnet

DFIG - Double Feed induction Generator

BDFG - Brush-less Doubly-Fed Generator
PTO - Power Take-Off

AC - Altern Current

CFTS - Contact-less Force Transmission System

OWC - Oscillating Water Column

DTC - Direct Torque Control

PLC - Programmable Logic Controller

$\mathrm{FC}-$ Frequency Converter

\section{Introduction}

This paper presents the analysis made to select the appropriate electrical generator for a new design of Wave Energy Converter (WEC), identifying the features that have influence on the WEC's performance, the efficiency and economical feasibility of the system.

The proposed WEC is a near shore submerged converter that takes advantage of the oscillating water column created by the wave when it passes on the converter's platform. The wave column moves the platform, transmitting the force to a single acting cylinder, that pumps sea water to the coast, where is turbined generating electricity. A constant flow is obtained by means of accumulators located inside the module. The nominal power of the facility depends on the number of modules connected in parallel, producing $25 \mathrm{~kW}$ per module. The facility size is between $100 \mathrm{~kW}$ ( 4 modules) and $500 \mathrm{~kW}$ (20 modules).

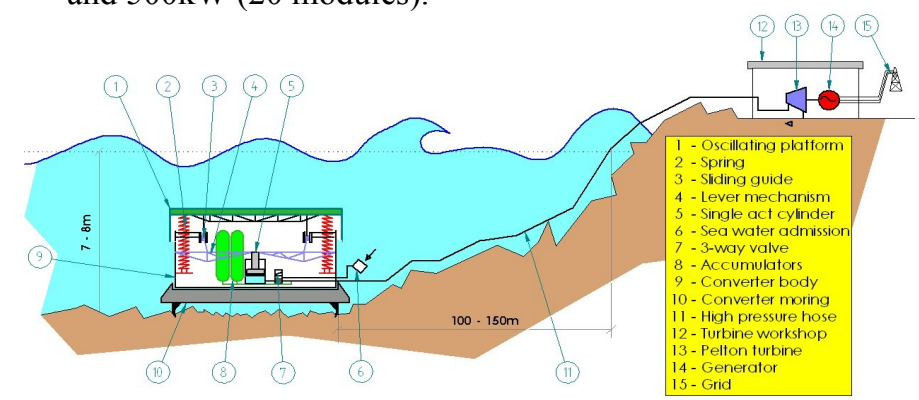

Fig. 1. Proposed WEC diagram

In a wave power plant, the input energy has no sustainable trend and its variation depends on the wave 
condition, that is, height and period of the waves. The regulation of these variations for optimising the energy absorption is achieved by changing WEC's working conditions, increasing system complexity and cost. The decision of use variable or constant speed should be based on efficiency and economical issues. Selection of an optimal generator requires the following considerations:

1. The generator should be as simple as possible while tolerating the variable electromechanical tensions

2. Maximum generated power

3. Justifiable cost addition in case of variable speed strategy in terms of efficiency and investment return

4. Control systems should be minimally necessary and sufficient, and economically justified

5. Minimum maintenance requirements

\section{Review of the electrical generators selected by other conversion systems}

There is a wide variety of energy conversion chains associated with harnessing power from wave and tidal current. These variations are associated with both the mechanical as well as electrical sub-conversion systems. For an example, a particular conversion process could have air turbines or hydraulic turbines or hydraulic pumps or reciprocating devices or propeller types. There are also different types of electrical generators that are used in the conversion chain, such as, synchronous, induction, permanent magnet, or linear generation [1]. Ocean power generators may or may not have governors or voltage regulators, and they may be connected through inverters or other types of power conversion equipment; therefore there are many options to be considered. A brief review of the generators chosen by other conversion system is presented, most of them prototypes.

- Pico (Portugal): The European Wave Energy Pilot Plant in the Azores archipelago is an OWC shoreline plant rated $400 \mathrm{~kW}$ equipped with an air turbine of the Wells type and an asynchronous generator, with a Kramer link. The turbo-generator set can operate between 750 (generator's synchronous speed) and $1500 \mathrm{rpm}$ [2].

- Mutriku: Developed by Wavegen (UK) in 2009, this wave energy plant consists of 16 chambers; in each one, the top opening is connected to a turbogenerator set with a rated capacity of $18.5 \mathrm{~kW}$, giving a total capacity of $296 \mathrm{~kW}$. The selected generator has been the synchronous PMG combined with a frequency inverter. This plant has been the first commercial OWC deployed plant [3].

- Wave Dragon (Denmark): This offshore overtopping device has been developed in Denmark. It utilizes a wave reflector design to focus the wave towards a ramp and fill a higher-level reservoir. Electricity is produced by a set of low-head Kaplan turbines. Efficient operation over the wide discharge range is ensured by using 16 relatively small turbines that can be switched on and off individually rather than a few large turbines. In order to grant a high efficiency throughout the wide head range, the turbines are operated at variable speed. Generators could be standard asynchronous or synchronous machines. A mixed set of turbines with fixed speed and asynchronous generators and variable speed turbines with synchronous generators of the PMGtype could turn out to be the preferred solution [2] [4].

- Salter's duck: the Edinburgh group developed an oscillating body, divided inside by two chambers. The pressure difference between the chambers moves the variable displacement radial pistons, which axle is coupled to a synchronous generator, working in constant speed. At that time (70's) the use of power electronics to work in variable speed was not enough developed [2].

- Archimedes Wave Swing, AWS (Holland, UK): The AWS consists of a hollow, pressurised steel structure, the upper part of which is initiated to heave motions by the periodic changing of hydrostatic pressure beneath a wave. A full-scale model of AWS was deployed in Portugal in 2004. The generator system consists of a permanent magnet linear synchronous generator with a current source inverter [5].

- Direct Drive Ocean Wave Energy Converter (USA): The device developed by the Oregon State University, employs a contact-less force transmission system (CFTS) to couple a float to the power take-off (PTO) mechanism made up of a ball screw, unidirectional clutch and a permanent magnet generator [6].

- Wave Energy Point Absorber (Greece): This WEC converts the wave motion to high pressure hydraulic energy by a floater driving a piston system anchored to the seabed. The piston system pressurizes seawater to 200bar, which is transferred to the shore to drive a hydraulic motor and produce electricity. The motor drives a synchronous generator at $3000 \mathrm{rpm}$. In the case of a floater array, several floaters are connected to a common PTO. The electrical power output is estimated to $2-3 \mathrm{~kW}$ per floater at moderate wave power levels $(10 \mathrm{~kW} / \mathrm{m})$ [2].

- Wavebob (UK): The Wavebob comprises a wave energy absorber and a hydraulic power take-off system driving synchronous alternators. The absorber is an axi-symmetric, compound, and selfreacting floater oscillator operating primarily in the heave mode. The Wavebob has been designed for offshore deployment in large arrays. Each Wavebob unit will carry three $0.5 \mathrm{MW}$ alternators (giving in total a rated output of $1.5 \mathrm{MW}$ ) driven at constant speed by hydraulic motors operating off oil pressure accumulators [2].

- Kobold (Italy): The Kobold is a vertical axis tidal current turbine. The device employs a vertical axis rotor driving a synchronous generator. An important feature of the Kobold is that the direction of rotation of the rotor is independent of the current direction. In 2002 a prototype was deployed in the Strait of Messina. The rotor has a diameter of6 $\mathrm{m}$ and 
consists of three blades with a span of $5 \mathrm{~m}$ each. It drives an alternator through an epicycloidal overgear. The tests indicate that the turbine produces $25 \mathrm{~kW}$ of power in a current speed of $1.8 \mathrm{~m} / \mathrm{s}$. In a current of $3.0 \mathrm{~m} / \mathrm{s} 80 \mathrm{~kW}$ are expected. [2].

- SEAFLOW Marine Current Turbine Rotational speed control (Ireland): A tidal current turbine similar to the Italian Kobold. A frequency converter controlling the full power of the synchronous generator allows full control of the turbine speed [2].

The converters listed utilise different working principles and are representative of the $R \& D$ current trends in wave energy. The review shows that there is not a predominant solution used widely by the different WEC solutions. Some of them use variable speed strategy in order to increase the efficiency (Pico plant, WaveDragon, Kobold, Seaflow), whereas others work under constant speed (WEPA, Wavebob, Salter's Duck). AWS and Direct Drive WEC use a linear synchronous generators, so they are not representative in this study.

Most of generators that make use of variable speed (Pico plant, Kobold, Seaflow), are PMG with frequency inverters, meanwhile the WaveDragon uses asynchronous and synchronous PM generators. Actually the use of these two technologies are generalised in variable speed applications, as it is going to be explained in Section 2 . The reliability of the synchronous PMG type make more suitable for offshore deployment. The Pico Plant is located onshore, but ten years ago the induction asynchronous generators where an emerging technology, and the island grid stability was in question as well, that is the reason of choosing the synchronous generator. It is remarkable that the newly installed Mutriku OWC onshore plant uses PMG as well. And synchronous generators are selected for constant speed applications (WEPA, Wavebob, Salter's Duck).

The AWS uses a similar working principle but as commented before, it uses a linear generator. On the other hand, WEPA and Wavebob use a point absorber (a buoy) as working principle, but shares the same PowerTake-Off (PTO) with the proposed WEC: the WEPA located onshore and using high pressure sea water; and the Wavebob integrated in the buoy by means of high pressure oil. Both use a hydraulic engine coupled to the generator, and both work with constant rotation speed though synchronous generator. To work at constant speed means that they may not take advantage of the maximum possible efficiency of the engine at any wave conditions.

\section{Electrical generator types}

Generators transform mechanical energy into electrical energy. A number of different drive concepts are being evaluated, inspired by previous developments, mainly in wind power and mini hydro power plants. There are two main generator families: the asynchronous and the synchronous altern current generators. [7].
- Synchronous generators: This type of generator runs at a constant speed and draws its excitation from a power source external or independent of the load or transmission network it is supplying. They are equipped with a DC electric or permanent magnet excitation system (rotating or static) associated with a voltage regulator to control the output voltage before the generator is connected to the grid. They supply the reactive energy required by the power system when the generator is connected to the grid. The permanent magnet excitation system has cornered the market in small medium size generators due to its simplicity, improved feasibility and the elimination of energy losses in the rotor. To work with variable speed, it includes a frequency inverter, composed by a rectifier that transforms the slip frequency ranges and currents into DC voltages and currents, and an inverter that transforms DC voltages and currents in synchronous frequency voltages and currents. By controlling the inverter it is possible to control the electromagnetic torque and, therefore, the speed of the set turbinegenerator.

- Asynchronous generators: If a three-phase asynchronous motor is driven over-synchronously through a driving machine, the direction of energy will be changed because of the negative slip. The motor passes over to generator operation and supplies the mains with energy. In this case, the generator takes the necessary reactive power from the grid, and additional excitation systems are not necessary. The grid maintains voltage and frequency so that separate regulators are not necessary. A variation of the induction generator can work with variable speed too: the DFIG (Double Fed Induction Generator. It is based on an induction generator with a multiphase wound rotor and a multiphase slip ring assembly with brushes for access to the rotor windings. It is possible to avoid the multiphase slip ring assembly, BDFG (Brushless Doubly-Fed Generator) improving system reliability. The principle of the DFIG is that rotor windings are connected to the grid via slip rings and back-to-back voltage source converter that controls both the rotor and the grid currents. Thus rotor frequency can freely differ from the grid frequency $(50$ or $60 \mathrm{~Hz}$ ). By controlling the rotor currents by the converter it is possible to adjust the active and reactive power fed to the grid from the stator independently of the generators turning speed. The control principle used is either the two-axis current vector control or Direct Torque Control (DTC). The cost of the converter is low when compared with other variable speed solutions because only fraction of the mechanical power, typically $25-30 \%$, is fed to the grid through the converter, the rest being fed to grid directly from the stator.

Summarising, there are two generator types suitable for variable speed operation: the synchronous permanent magnet generator (PMG) with the frequency inverter and the asynchronous induction generator. On the other hand, for constant speed operation the synchronous PMG and the squirrel-cage induction generator fulfil the requirements. However, before selecting the generators, it is 
mandatory to study the operation of the generator and the status of the host power network of which the generator will be a component. A comparison of the characteristics of each type of generator is listed,

- Excitation: The synchronous generators with permanent magnet are free from exciting coils, as asynchronous ones because the necessary power for excitation the armature coils should be drawn from the power network.

- Speed: Due to the use of a Pelton turbine, the rotation speed is high, which leads the use of compact generators, avoiding the use of a gearbox.

- Independent Operation: Synchronous generators can run isolated from the grid and produce power since excitation is not grid-dependent, while the operations of asynchronous ones need to be fed with an exciting current from the power network. When using asynchronous generators in isolated operation, the excitation is conducted through a parallel connection of a capacitor bank. Its dimensioning depends on the generator power and on the generator parameters. The operating mode is considerably more expensive than the parallel operation with the network and is only used for lower outputs. Furthermore there is to be emphasized that an isolated generator reacts sensitively to inductive consumer units and speed variations.

- Voltage regulation: The output voltage of the synchronous generator terminals can be regulated but the voltage of the asynchronous generators always matches the voltage of the power network.

- Power factor control: In synchronous generators, the power factor of the front and rear phases and the reactive power can be controlled. The asynchronous generators work with the power factor of rear phase and a condenser is required for any correction of the power factor.

- Paralleling with the power network: For synchronous generators, this is a complex control that requires regulation of the voltage, frequency and phase. But for asynchronous generators, the control is simpler as paralleling is done only at the synch speed.

- Impact on power network during paralleling: For synchronous generators, no impact is generated during connection to the network, but some additional currents will flow in asynchronous generators that produce no voltage before connection to the network and this necessitates consideration of any drop in the network.

- Cost: The cost for the frequency converter is an important consideration. Below $1 \mathrm{MW}$, synchronous generators are more expensive than asynchronous generators and are used in power systems where the output of the generator represents a substantial proportion of the power system load. Asynchronous generators are cheaper and are used in stable grids where their output is an insignificant proportion of the power system load.

- Efficiency: The efficiency should be $95 \%$ for a 100 $\mathrm{kW}$ machine and can increase to $97 \%$ towards an output power of 1MW. Efficiencies of synchronous generators are slightly higher, specially for low rated powers. Table 1 presents a comparison between both generators collected from two generator's manufacturers Marelli [9], and VEM [10]).

(FKI

Table 1 Efficiencies comparison for the PMG and DFIG at the rated power [9], [10]

\begin{tabular}{|l|c|c|c|c|c|}
\hline $\begin{array}{l}\text { Rated power } \\
(\mathrm{kW})\end{array}$ & 10 & 50 & 100 & 250 & 420 \\
\hline $\begin{array}{l}\text { PMG (sync.) } \\
\text { efficiency }\end{array}$ & 0,91 & 0,94 & 0,95 & 0,96 & 0,96 \\
\hline $\begin{array}{l}\text { DFIG (async.) } \\
\eta, \text { efficiency }\end{array}$ & 0,863 & 0,935 & 0,946 & 0,955 & 0,96 \\
\hline
\end{tabular}

Part load efficiency is also an important figure of merit. PM synchronous generators with frequency converters appear relatively efficient at part load [8]. The efficiency loss for asynchronous maintains the efficiency at $3 / 4$ of the load, losing up to $1,5 \%$ working at half load [9].

Rated outputs refer to an installation height up to $1.000 \mathrm{~m}$ and to a maximum ambient temperature of $40^{\circ} \mathrm{C}$. For higher altitudes and different temperature values the rated outputs must be recalculated using correction factors [9].

\section{WEC's control strategy}

The dynamic behaviour of the platform combines two motions:, low frequency motion due to changes in tide (slow dynamics); and high frequency motion due to the sea waves (fast dynamics). The energy absorbed by the WEC is maximum when platform's movement is tuned to the incident wave frequency [11]. The PLC acts on the following features to achieve the resonance [12],

- System pressure: the cylinder must create the appropriate resistance to match the coming wave size. System pressure is adapted acting on turbine jet overture, controlling its needle position.

- Generator's load torque: the output power is estimated according to the working pressure and the flow. The synchronous generator load torque signal is set according to the estimated power and turbine's optimal rotation speed (that depends only on system's pressure).

The operation of the WEC is described in Fig. 2. The wave size (height and period) are tracked by a measuring buoy or a pressure sensor. Based on these data, the PLC knows the current available energy, and the implemented control algorithm [12] calculates the optimum system pressure in order to maintain the resonance with the waves. The desired pressure is achieved acting on the needle valve located in the Pelton turbine jet. The second part of the control is related with the turbine-generator set. There are two options: to work with variable speed to take advantage of the highest efficiency, or work with constant speed, reducing the initial investment. In both cases the PLC sets the generators load with the available wave size information for the given rotation speed (variable or fixed). The Pelton turbine has a particular high efficiency rotation speed for a given system 
pressure, this would be the advantage of working with variable speed.

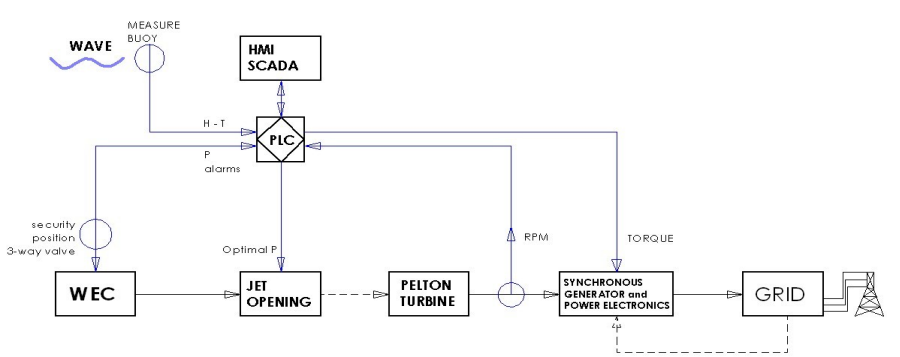

Fig. 2 Control schema of the proposed WEC

\section{Implementation of the different generators on WEC's control}

The selection of the generator does not have influence on optimal pressure control algorithm, but it sets the electrical generation stage control. The following sections describe different generation systems adapted to the proposed WEC.

\section{A. Synchronous Permanent Magnet Generator with fre- quency inverter}

The synchronous PMG with frequency inverter allows the energy generation with variable speed, improving the system efficiency.

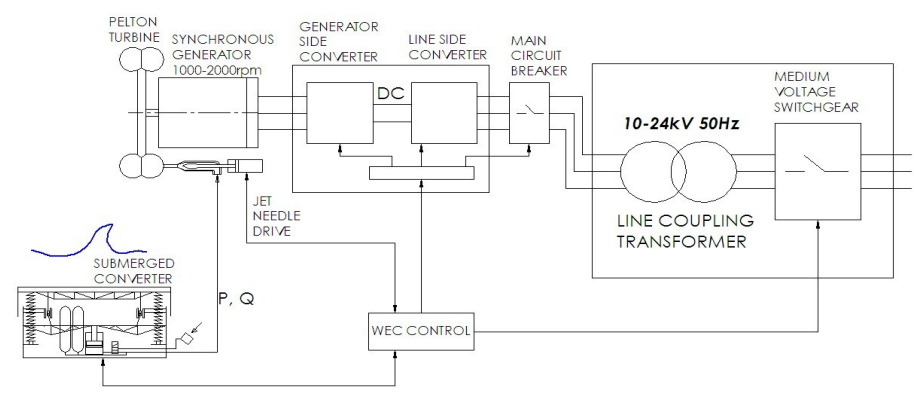

Fig. 3 Control schema for a synchronous PMG with frequency inverter

The variable speed performance is made through a frequency inverter, composed by a rectifier that transforms the slip frequency ranges and currents into DC voltages and currents, and an inverter that transforms DC voltages and currents in synchronous frequency voltages and currents. By controlling the inverter it is possible to control the electromagnetic torque and, therefore, the speed of the set turbine-generator.

Therefore its integration in the WEC's control needs an estimation of the generator's load torque, derived from WEC working parameters, and the targeted rotation speed (turbine optimal rotation speed). The actual speed is monitored by the PLC to compare the difference between the actual and desired sped. Figure 3 defines the control schema of the WEC using a synchronous PMG with frequency inverter. As explained before, the control of the generator does not affect on the pressure algorithm of the converter.

\section{B. Asynchronous Double-Feed Induction Generator}

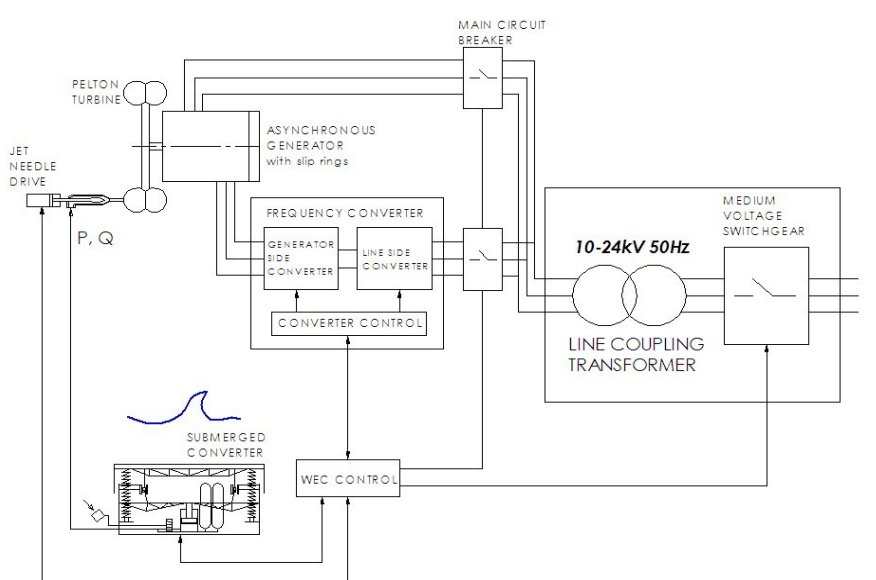

Fig. 4 Control schema for an asynchronous induction generator with converter

Produces alternating current that matches an existing power source with no possibility of voltage regulation and running at a speed directly related to system frequency. At a partial load the generator torque is regulated by the converter. Figure 4 shows the control schema of the WEC implementing the DFIG with FC.

To work with variable speed, four quadrant control is used (voltage $\mathrm{V}_{\mathrm{r}}$ and reactive power $\mathrm{Q}_{\mathrm{R}}$ ), creating a bidirectional, speed synchronized, multiphase electrical power at one of the winding. It is economical concept to obtain a variable speed and reactive power, and to increase the energy yield. The data needed to control the generator is the expected power provided by the WEC (according to its working parameters and wave conditions), the optimal rotation speed (that depends only on the working pressure), and reactive power. The grid regulator authorities may be interested in set the generated reactive power when operating the grid. But the small rated power may be not interesting for network operation. In other case, adding a bank of capacitors the absorbed reactive energy can be compensated.

\section{Synchronous Permanent Magnet Generator (constant speed)}

Another choice could be to work in constant speed, losing efficiency at the turbine, but gaining simplicity, robustness and feasibility, reducing the initial investment at the same time. Figure 5 presents the WEC control implemented with a PMG without frequency converter.

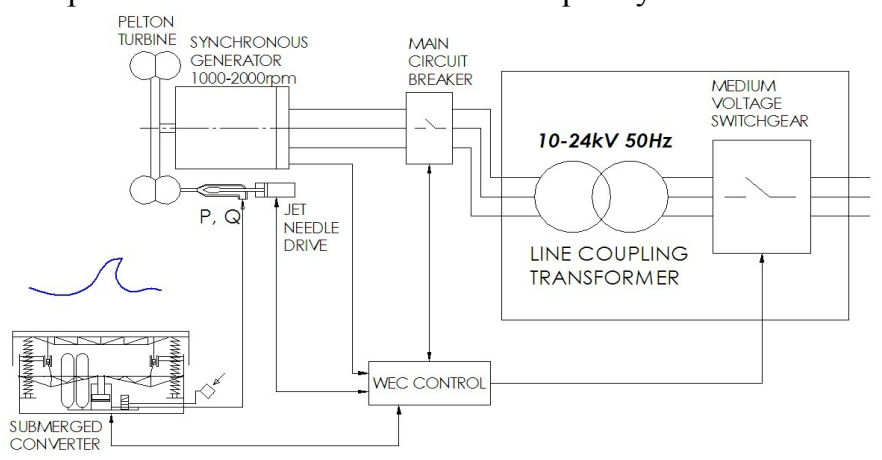

Fig. 5 Control schema for a synchronous permanent magnet generator that works at constant speed 
This generator also needs a forecasting of the expected energy provided by the WEC in order to control and maintain the synchronism speed of the machine. The constant speed must depend on the generator's load torque instead of turbine jet regulation, resulting the WEC's optimal working pressure unaffected.

\section{Asynchronous Induction Generator (constant speed)}

The asynchronous generator can also work with constant speed, absorbing the required excitation from the grid, matching its frequency and voltage. It is an economical generator with the drawback that it can not work in isolate mode. Figure 6 implements the induction generator with squirrel-cage rotor in the proposed WEC.

In this case there is no reactive power control, using a bank of capacitors to compensate it. No signal is needed to control the generator, regulating itself according to the grid voltage and frequency.

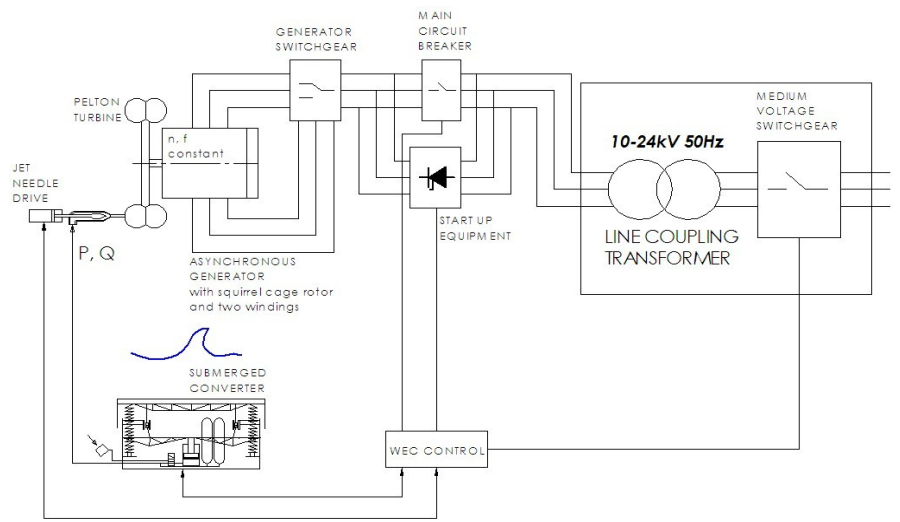

Fig. 6. Control schema for an asynchronous induction generator working at constant speed

\section{Discussion about variable or constant speed strategy}

On one hand, the electrical energy generation field demands for the highest efficiency in order to harvest the maximum energy with the same installation. On the other hand, a variable speed strategy requires a greater initial investment, longer investment return and it involves more complexity (less reliability). This section analyses the energy output difference between variable and constant speed strategies. The study is based on the efficiency of the turbine for both dispositions, followed by a evaluation of the energy loss for a given location, applied as example on a hypothetical implantation in Bilbao Port.

\section{A. Influence on the energy output}

The Pelton turbine efficiency depends only on the net height (working pressure for the proposed WEC). Usual hydropower plants have constant net height and they play with the flow to match the load and the constant speed requirement. In this case both, flow and pressure are variable, and they can not be used to regulate generator's speed or torque. Quite the opposite, the generator has to adapt its parameters to the converter's variable working conditions to absorb the maximum energy from the waves. After formulate the turbine efficiency, both strategies, variable and constant speed strategies, are compared to in order to quantify the loss. The comparison has been made for four submerged modules disposition, and a commercial turbine [14].

The ideal runner speed will cause all of the kinetic energy in the jet to be transferred to the wheel. That means that the exit velocity of the water must be zero in the runner [15]. Then the optimal runner speed (1) and consequently the turbines optimal speed (2) are,

$$
\begin{aligned}
& \mathrm{u}=\frac{\mathrm{v}_{\mathrm{J}}}{2}=\frac{\sqrt{2 \mathrm{gh}_{\mathrm{N}}}}{2} \\
& \mathrm{~N}_{\mathrm{OPT}}=\frac{\sqrt{2 \mathrm{gh}_{\mathrm{N}}}}{2} \cdot \frac{2}{\mathrm{D}_{\mathrm{T}}} \cdot \frac{60}{2 \pi}
\end{aligned}
$$

If the speed is set, the power also can be calculated (3), and the maximum power for each working pressure $\left(h_{N}\right)$ as well (4).

$$
\begin{aligned}
& \mathrm{P}=2 \rho \mathrm{Q}\left(\mathrm{v}_{\mathrm{J}}-\mathrm{u}\right) \mathrm{u} \\
& \mathrm{P}_{\mathrm{MAX}}=\frac{1}{2} \rho \mathrm{Qv}_{\mathrm{J}}^{2}=\rho \mathrm{gQh}_{\mathrm{N}}
\end{aligned}
$$

This quantity exactly equals the kinetic power of the jet, so in this ideal case, the efficiency is $100 \%$, since all the energy in the jet is converted to shaft output [15]. The wheel power divided by the initial jet power, is the turbine efficiency (5).

$$
\eta=4 \mathrm{u} \cdot \frac{\mathrm{v}_{\mathrm{J}}-\mathrm{u}}{\mathrm{v}_{\mathrm{J}}^{2}}
$$

As a design sample, the variable speed influence on efficiency has been applied on four submerged converters disposition connected in parallel. The turbine has been selected from Voith catalogue [14]: 1 jet horizontal shaft, 1a runner type and $1500 \mathrm{rpm}$ nominal speed $(50 \mathrm{~Hz})$. The converter is designed to work in a pressure range between 220 and $440 \mathrm{~m}$ net height. Table 2 shows the efficiency achieved for a given pressure supposing that the turbine works under different synchronous constant speeds, applying (1), (2) and (5) expressions.

Table 2 For each working pressure, jet lineal speed (1), the optimal rotation speed (2), and the efficiency for each synchronous speed (5) for $50 \mathrm{~Hz}$

\begin{tabular}{|c|c|c|c|c|c|c|}
\hline & & & \multicolumn{4}{|c|}{ Efficiencies (\%) } \\
\cline { 5 - 7 } $\mathbf{h}_{\mathbf{N}}$ & \multirow{2}{*}{$\begin{array}{c}\mathbf{V}_{\mathbf{J}} \\
(\mathrm{m} / \mathrm{s})\end{array}$} & $\begin{array}{c}\mathbf{N}_{\text {OPT }} \\
(\mathrm{rpm})\end{array}$ & $\begin{array}{c}\mathbf{p}=\mathbf{1} \\
\mathbf{3 0 0 0 r p m} \\
\mathbf{u}=\mathbf{7 9 m} / \mathbf{s}\end{array}$ & $\begin{array}{c}\mathbf{p}=\mathbf{2} \\
\mathbf{1 5 0 0 r p m} \\
\mathbf{u}=\mathbf{3 9 m} / \mathbf{s}\end{array}$ & $\begin{array}{c}\mathbf{p}=\mathbf{3} \\
\mathbf{1 0 0 0 r p m} \\
\mathbf{u}=\mathbf{2 6 m} / \mathbf{s}\end{array}$ & $\begin{array}{c}\mathbf{p}=\mathbf{4} \\
\mathbf{7 5 0} \mathbf{r p m} \\
\mathbf{u}=\mathbf{2 0 m} / \mathbf{s}\end{array}$ \\
\hline $\mathbf{2 2 0}$ & 65,7 & 1254 & $-97,7 \%$ & $96,5 \%$ & $95,7 \%$ & $84,7 \%$ \\
\hline $\mathbf{2 4 0}$ & 68,6 & 1310 & $-70,0 \%$ & $98,1 \%$ & $94,2 \%$ & $82,6 \%$ \\
\hline $\mathbf{2 6 0}$ & 71,4 & 1363 & $-47,2 \%$ & $99,1 \%$ & $92,6 \%$ & $80,7 \%$ \\
\hline $\mathbf{2 8 0}$ & 74,1 & 1415 & $-28,3 \%$ & $99,7 \%$ & $91,1 \%$ & $78,8 \%$ \\
\hline $\mathbf{3 0 0}$ & 76,7 & 1465 & $-12,5 \%$ & $100,0 \%$ & $89,6 \%$ & $77,1 \%$ \\
\hline $\mathbf{3 2 0}$ & 79,2 & 1513 & $1,00 \%$ & $100,0 \%$ & $88,2 \%$ & $75,5 \%$ \\
\hline $\mathbf{3 4 0}$ & 81,6 & 1559 & $12,5 \%$ & $99,8 \%$ & $86,8 \%$ & $74,0 \%$ \\
\hline $\mathbf{3 6 0}$ & 84,0 & 1604 & $22,4 \%$ & $99,5 \%$ & $85,5 \%$ & $72,6 \%$ \\
\hline $\mathbf{3 8 0}$ & 86,3 & 1648 & $31,0 \%$ & $99,1 \%$ & $84,2 \%$ & $71,2 \%$ \\
\hline $\mathbf{4 0 0}$ & 88,5 & 1691 & $38,5 \%$ & $98,6 \%$ & $83,0 \%$ & $69,9 \%$ \\
\hline $\mathbf{4 2 0}$ & 90,7 & 1733 & $45,0 \%$ & $98,0 \%$ & $81,8 \%$ & $68,7 \%$ \\
\hline $\mathbf{4 4 0}$ & 92,9 & 1774 & $50,8 \%$ & $97,4 \%$ & $80,6 \%$ & $67,6 \%$ \\
\hline
\end{tabular}


The efficiency values are obtained, first calculating the initial jet speed $v_{J}$ for each pressure value. Once the jet speed is known, the optimal rotation speed is easily obtained applying formula (2). Finally, applying formula (5), the efficiency is obtained for each synchronous speed in function of net height and linear speed of the runner $u$.

In case of $3000 \mathrm{rpm}$ generator, the runner linear speed is higher that jet speed, that is the reason of the negative efficiency values. Figure 7 reflects graphically the efficiencies shown in Table 2.

The best values are achieved at 1500rpm, as expected, because the converter has been designed according to this turbine working speed. In the working range, the turbine is optimised to work at $\sim 330 \mathrm{~m}$ net height, decreasing the efficiency at higher and lower working pressures. The efficiency loss range is enclosed in $3,5 \%$ in low pressures and $2,6 \%$ in high pressures. This loss seems small and can be assumable for a given settlement. Most waves are small so the the turbine will be working under conditions out of the optimal parameters most of the time. This can be improved modifying the turbine to displace the optimal working point to a lower net height, or moving up WEC's working pressure range.

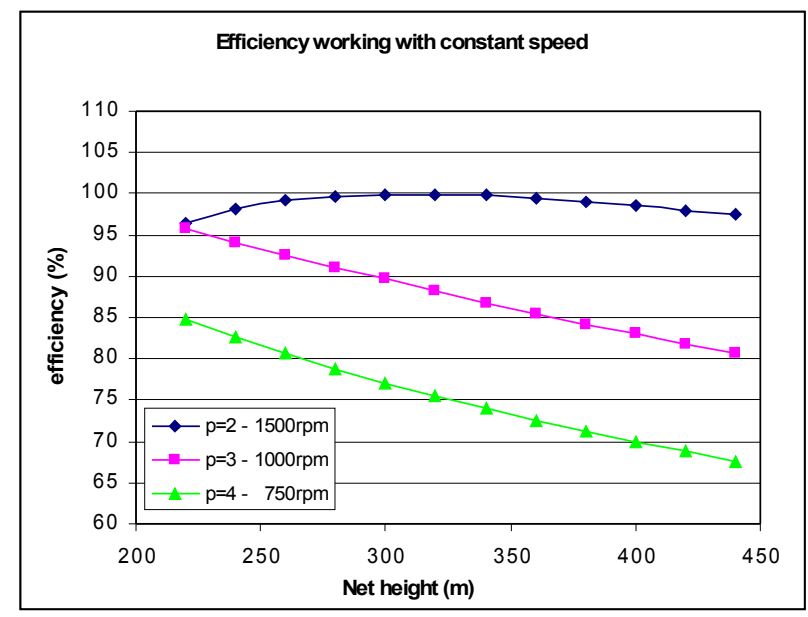

Figure 7 Efficiency values for each synchronous speed in function of the working pressure (net height, in meters)

\section{B. Energy loss evaluation for a given location}

The evaluation of the energy loss is presented for a given location as an example: the Bilbao Port. This procedure can be applied to another location being known its wave resource data.

The wave energy resource for a given location is defined by a bivariate distribution of significant wave height, $H s$ (m), and wave period, $T$, (s), counting the occurrences for each wave size and period during a given time period. Table 3 shows the wave resource available in Bilbao in 2008.

It is noticeable that small waves are the most repeated, bigger waves have longer periods, and some wave height-period combinations are not common. Matching the optimal working pressure for each wave condition (Formula (6), [12]), the correspondent jet speed is
Table 3. Bivariate distribution of the wave resource at Bilbao Port, 2008 [13]. Number of occurrences for each height period combination

\begin{tabular}{|c|c|c|c|c|c|c|c|r|}
\hline \multirow{2}{*}{$\begin{array}{c}\text { Hs } \\
(\mathrm{m})\end{array}$} & \multicolumn{7}{|c|}{ T period (s) } \\
\cline { 2 - 10 } & $\mathbf{5}$ & $\mathbf{6}$ & $\mathbf{7}$ & $\mathbf{8}$ & $\mathbf{9}$ & $\mathbf{1 0}$ & $\mathbf{1 1}$ & $\boldsymbol{\Sigma}=$ \\
\hline $\mathbf{2}$ & 439 & 1435 & 1036 & 414 & 119 & 35 & 5 & $\mathbf{1 6 0 9}$ \\
\hline $\mathbf{3}$ & 1 & 336 & 1012 & 533 & 215 & 32 & 8 & $\mathbf{2 1 3 7}$ \\
\hline $\mathbf{4}$ & & 176 & 630 & 346 & 87 & 5 & 1 & $\mathbf{1 2 4 5}$ \\
\hline $\mathbf{5}$ & & & 128 & 249 & 143 & 30 & 5 & $\mathbf{5 5 5}$ \\
\hline $\mathbf{6}$ & & & 1 & 78 & 135 & 45 & 4 & $\mathbf{2 6 3}$ \\
\hline $\mathbf{7}$ & & & & 2 & 57 & 52 & 11 & $\mathbf{1 2 2}$ \\
\hline $\mathbf{8}$ & & & & & 3 & 27 & 14 & $\mathbf{4 4}$ \\
\hline $\mathbf{9}$ & & & & 1 & & 3 & 9 & $\mathbf{1 3}$ \\
\hline & & & & & & $\boldsymbol{\Sigma}=$ & $\mathbf{8 2 0 3}$ \\
\hline
\end{tabular}

known, and therefore the efficiency expected for each wave condition using Formula (5). Table 4 reflects these values for a generator that rotates at $1500 \mathrm{rpm}$ synchronous speed.

$$
\mathrm{h}_{\mathrm{N}}^{\mathrm{OPT}}=\frac{4}{10^{4} \pi \mathrm{D}_{\mathrm{c}}^{2} \mathrm{c}}\left(62,5 \mathrm{H}^{2} \mathrm{~T}\right)
$$

Table 4 Efficiencies for each wave size condition working at $1500 \mathrm{rpm}$ constant speed, obtained using the optimal pressure algorithm, the grey positions are not common waves or they are under minimum design wave size $(<\mathrm{Hs} 2 \mathrm{~m}-\mathrm{T} 7 \mathrm{~s})$

\begin{tabular}{|c|c|c|c|c|c|c|c|}
\hline \multirow{2}{*}{$\begin{array}{c}\text { Hs } \\
(\mathrm{m})\end{array}$} & \multicolumn{7}{|c|}{ T period (s) } \\
\cline { 2 - 8 } & $\mathbf{5}$ & $\mathbf{6}$ & $\mathbf{7}$ & $\mathbf{8}$ & $\mathbf{9}$ & $\mathbf{1 0}$ & $\mathbf{1 1}$ \\
\hline $\mathbf{2}$ & $89,1 \%$ & $93 \%$ & $95,4 \%$ & $98,8 \%$ & $100 \%$ & $98,8 \%$ & $95,6 \%$ \\
\hline $\mathbf{3}$ & $95,2 \%$ & $97,6 \%$ & $99,5 \%$ & $99,9 \%$ & $98,4 \%$ & $94,9 \%$ & $90,0 \%$ \\
\hline $\mathbf{4}$ & $98,5 \%$ & $99 \%$ & $100 \%$ & $99,4 \%$ & $97,3 \%$ & $93,7 \%$ & $88,8 \%$ \\
\hline $\mathbf{5}$ & $99,8 \%$ & $100 \%$ & $99,3 \%$ & $97,2 \%$ & $93,6 \%$ & $88,6 \%$ & $82,8 \%$ \\
\hline $\mathbf{6}$ & $99,8 \%$ & $99 \%$ & $98,0 \%$ & $95,5 \%$ & $91,8 \%$ & $87,0 \%$ & $81,4 \%$ \\
\hline $\mathbf{7}$ & $98,9 \%$ & $98 \%$ & $96,5 \%$ & $93,9 \%$ & $90 \%$ & $85,6 \%$ & $80,3 \%$ \\
\hline $\mathbf{8}$ & $96,8 \%$ & $95 \%$ & $93,0 \%$ & $89,6 \%$ & $85 \%$ & $79,9 \%$ & $74,1 \%$ \\
\hline $\mathbf{9}$ & $93,0 \%$ & $91 \%$ & $88,9 \%$ & $85,5 \%$ & $81 \%$ & $76,1 \%$ & $70,6 \%$ \\
\hline
\end{tabular}

The worst efficiency values are obtained on big waves with long periods, the ones that have more energy. The energy loss range for the most repeated waves conditions is limited to $5-10 \%$. This loss is significant and it can be considered inadmissible to apply on big power facilities. In case of working with variable speed, the only losses would be the electrical and hydraulic losses.

The maximum power that can be absorbed by means of variable speed strategy is given by Formula (7). Being known the pressure and discharge flow data for each wave condition, a similar Hs-T table is obtained (Formula (8)). Multiplying these values by its correspondent wave condition at the wave resource distribution (number of occurrences, Table 3), we can estimate the energy output for the location that is being studied (Formula (9)). Actually, the power output by occurrence number is an energy value, as $\mathrm{kW} \cdot \mathrm{h}$ is an 
energy unit. And finally, multiplying each data of this table by its correspondent efficiency, defined before in Table 4, the real output expected is obtained in a similar bivariate table (Formula (10)).

$$
\begin{aligned}
& \mathrm{P}_{\mathrm{MAX}}^{\mathrm{H}, \mathrm{T}}=\rho \cdot \mathrm{g} \cdot \mathrm{h}_{\mathrm{N}} \cdot \mathrm{Q} \\
& \mathrm{P}_{\text {real }}^{\mathrm{H}, \mathrm{T}}=\eta_{\mathrm{PT}} \cdot \rho \cdot \mathrm{g} \cdot \mathrm{h}_{\mathrm{N}} \cdot \mathrm{Q} \\
& \mathrm{E}_{\mathrm{MAX}}^{\mathrm{H}, \mathrm{T}}=\mathrm{P}_{\mathrm{MAX}}^{\mathrm{H}, \mathrm{T}} \cdot(\text { occ })^{\mathrm{H}, \mathrm{T}} \\
& \mathrm{E}_{\text {real }}^{\mathrm{H}, \mathrm{T}}=\eta^{\mathrm{H}, \mathrm{T}} \cdot \mathrm{P}_{\mathrm{MAX}}^{\mathrm{H}, \mathrm{T}} \cdot(\text { occ })^{\mathrm{H}, \mathrm{T}}
\end{aligned}
$$

Instead of presenting all height-period combinations, the results have been summarised in one table, arranged by the significant wave height, summing the different values obtained at different $\mathrm{T}$ periods for the same wave height, and it includes their percentage regarding the total. Table 5 meets this aim and it presents:

- n. of occ., the occurrences for each wave height, it represents the weight or importance of each wave size $\mathrm{E}_{\mathrm{MAX}}^{\mathrm{H}}$, the maximum energy available for each wave height, calculated with Formula (9)

- $\mathrm{E}_{\text {real }}^{\mathrm{H}}$, the real energy available for each wave height, calculated with Formula (10)

- $\Delta \mathrm{E}^{\mathrm{H}}$, difference between $\mathrm{E}_{\mathrm{MAX}}-\mathrm{E}_{\text {real }}$ in percentage regarding the maximum energy for a given wave height

$$
\Delta \mathrm{E}^{\mathrm{H}}=\frac{\mathrm{E}_{\mathrm{MAX}}^{\mathrm{H}}-\mathrm{E}_{\text {real }}^{\mathrm{H}}}{\mathrm{E}_{\mathrm{MAX}}^{\mathrm{H}}} \times 100
$$

- $\% \mathrm{~L}^{\mathrm{H}}$, proportion of the loss energy regarding the total energy loss

$$
\Delta \mathrm{L}^{\mathrm{H}}=\frac{\mathrm{E}_{\mathrm{MAX}}^{\mathrm{H}}-\mathrm{E}_{\text {real }}^{\mathrm{H}}}{\sum \mathrm{E}_{\mathrm{MAX}}-\sum \mathrm{E}_{\text {real }}} \times 100
$$

Table 5. Summary arranged according to significant wave height, $H s$. The table includes the number of occurrences, the maximum energy $\left(\mathrm{P}_{\mathrm{MAX}} * \mathrm{Occ}\right)$, the real energy $\left(\mathrm{h} * \mathrm{P}_{\mathrm{MAX}}{ }^{*} \mathrm{occ}\right)$, the difference between $\mathrm{E}_{\mathrm{MAX}}-\mathrm{E}_{\text {real }}$ in \%, and the proportion of this loss compared to the total loss in $\%$

\begin{tabular}{|c|c|r|r|r|r|}
\hline $\begin{array}{c}\mathbf{H s} \\
(\mathbf{m})\end{array}$ & $\mathbf{n . ~ o f ~ o c c . ( \% )}$ & $\mathbf{E}_{\mathbf{M A X}}^{\mathbf{H}}$ & $\mathbf{E}_{\text {real }}^{\mathbf{H}}(\mathbf{\%})$ & $\mathbf{\%} \Delta \mathbf{E}^{\mathbf{H}}$ & $\mathbf{\%}^{\mathbf{H}}$ \\
\hline$>2$ & $2215(27 \%)$ & $(0)$ & $(0)$ & $(0)$ & $(0)$ \\
\hline 2 & $1609(19.6 \%)$ & 120,7 & $116,7(20.9 \%)$ & $3,22 \%$ & $28,3 \%$ \\
\hline 3 & $2137(26 \%)$ & 205,8 & $203,9(36.5 \%)$ & $0,91 \%$ & $13,7 \%$ \\
\hline 4 & $1245(15.2 \%)$ & 133,9 & $133,3(23.9 \%)$ & $0,46 \%$ & $4,5 \%$ \\
\hline 5 & $555(6.8 \%)$ & 65,3 & $62,9(11.3 \%)$ & $3,62 \%$ & $17,2 \%$ \\
\hline 6 & $263(3.2 \%)$ & 28,8 & $26,5(4.8 \%)$ & $7,78 \%$ & $16,3 \%$ \\
\hline 7 & $122(1.5 \%)$ & 12,4 & $10,8(1.9 \%)$ & $12,3 \%$ & $11,1 \%$ \\
\hline 8 & $44(0.5 \%)$ & 4,2 & $3,2(0.6 \%)$ & $21,4 \%$ & $6,5 \%$ \\
\hline 9 & $13(0.2 \%)$ & 1,2 & $0,8(0.2 \%)$ & $26,6 \%$ & $2,3 \%$ \\
\hline$\Sigma=$ & $\mathbf{8 2 0 3}$ & $\mathbf{5 5 8 , 4}$ & $\mathbf{5 5 8 , 5 ( 1 0 0 \% )}$ & $\mathbf{2 , 4 \%}$ & $\mathbf{1 0 0 \%}$ \\
\hline
\end{tabular}

The loss percentage for a given wave size column $(\% \Delta \mathrm{E})$, starts at $\sim 3 \%$ for $2 \mathrm{~m}$ wave, decreases to $0,5 \%$ at $4 \mathrm{~m}$ height, increasing again exponentially, achieving a $26 \%$ loss at $9 \mathrm{~m}$ wave. The turbine is designed to bring the maximum output at the middle of the working range, and therefore, the WEC has been designed to fit in that range. But the small waves are the most repeated, so they meaning the $\% 30$ of the total loss. Even only $73 \%$ of the energy is useful for $9 \mathrm{~m}$ waves, they are not often repeated, and they only represent the $3,3 \%$ of the losses. Reducing the optimal working pressure of the turbine, or increasing the minimum pressure of the WEC, could decrease the overall losses, distributing the working pressure in an asymmetric way.

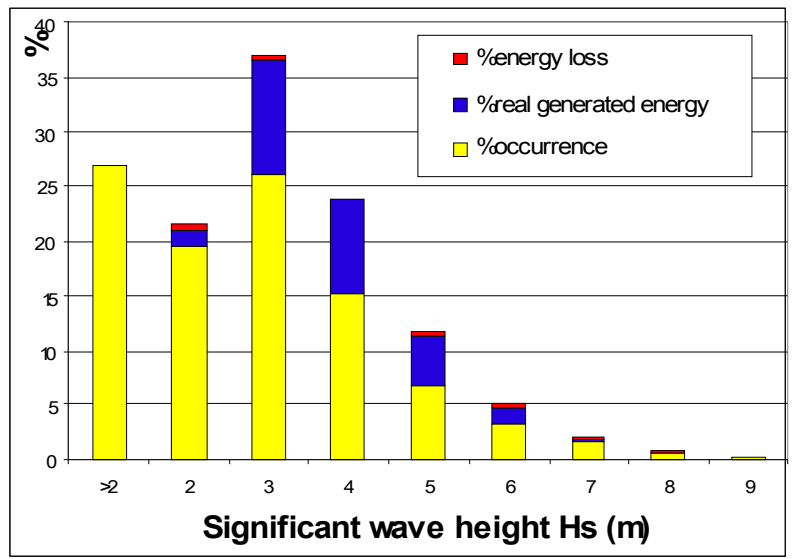

Fig. 8 Table 5 presented in a column graph

\section{Economical feasibility study}

Beside the variable-constant speed strategy influence on the efficiency and expected energy output for a given location, the initial cost of the facility and the exploitation cost (maintenance and reactive energy requirements) are decisive when studying the feasibility of the investment [17]. This section analyses these aspects related to the investment return.

\section{A. Initial cost}

The benefits of variable speed efficiency gain may be not worthy of implement, if the investment represents a significant proportion of the total investment. The initial investment cost represents a milestone in the evaluation of the economical feasibility of the investment.

It is remarkable that due to the high working pressure, low discharge rates and the use of an small Pelton turbine, the required rotation speed is high, 1500rpm, then a gearbox is not needed, reducing substantially the initial and maintenance costs. This implies that the required generator is smaller, cheaper and has better efficiency that the one that work with low speed.

The generators data have been obtained obtained from FKI Marelli (synchronous and asynchronous) [9] and VEM (asynchronous) [10], being both leading companies in small size generators. The prices have been provided be their local dealers, respectively for $110 \mathrm{~kW}$ and $350 \mathrm{~kW}$ rated power. Regrettably, the price of the FC was not included in the offer provided by the dealers, so the real cost is unknown. The read literature denotes the variation 
of the generator prices year by year, due to the continuous development of technologies and markets.

According to the prices provided by the dealers, asynchronous generators are circa $15 \%$ cheaper than synchronous ones. The $€ / \mathrm{kW}$ ratio increases with the rated power for the asynchronous generators, being this ratio similar for the synchronous generators. The price of the generator represents circa $33-22 \%$ of the cost of the facility. As commented before, we have not the prices of the FCs.

Any comprehensive analysis and comparison needs to consider other factors like efficiency, maintenance costs, reliability, costs of reactive power, and many other factors like network. The efficiency difference between both generators types, beside the improved turbine efficiency working with variable speed, will define the investment return period, for a given location and installed power.

\section{B. Efficiency}

After accomplish the initial investment, high efficiency and low exploitation costs can help to recoup faster the investment, maximising future profits. Therefore the efficiency is an important parameter to be regarded in any feasibility study.

The efficiency gain using variable speed has been studied in Section 6.1, and the expected output power in a given location in Section 6.2. The efficiency can be increased up to $5 \%$ using variable speed, but it may be not interesting due to the low power rate. The efficiency difference between synchronous and asynchronous generators has been described in Section 3 (Table 1). Disregarding rated powers lower than $100 \mathrm{~kW}$, the achieved efficiencies are similar, slightly lower in case of induction generators. The hydraulic losses [16] have not been taken into account in this paper due to they are not related with the electrical energy conversion chain.

\section{Maintenance cost}

The PM generator have improved its feasibility, decreasing significantly the maintenance cost respecting the synchronous generators applied in small-medium size facilities used before. A brushless double-feed induction generator exits, but its application is not extended due to the technology is new and under patent. That means that the available commercial DFIGs still use slip rings, which increases the maintenance costs. It is expected that in the near-term future, the brushless technology will be widely available.

One of the characteristics of the Pelton turbine is that works under high rotation speeds, which means smaller generators and avoids the use of gearboxes. The gearboxes are called the 'mechanic fuse' of wind towers, which require rigorous maintenance.

\section{Reactive power}

The use of induction generators would require capacitors for reactive power at an additional cost, not included in the initial cost comparison of this section. This sentence can be applied to the squirrel-cage generators in isolated operation.

\section{E. Network}

Synchronous generators can run isolated from the grid and produce power since excitation is not grid-dependent, while the operations of asynchronous ones need to be fed with an exciting current from the power network.

When using asynchronous generators in isolated operation, the excitation is realised through a small synchronous generator for the magnetisation or the parallel connection of a capacitor bank. Its dimensioning depends on the generator power and on the generator parameters. The operating mode is considerably more expensive than the parallel operation with the network and is only used for lower outputs. Furthermore there is to be emphasized that an isolated generator reacts sensitively to inductive consumer units and speed variations.

\section{Conclusions}

We have found necessary and valuable to accomplish this review and reflection about the selection of the generator. The influence of the generator on converter's performance has been studied, as well as its implementation in the system's control. In addition, an example of feasibility study has been applied on a given disposition to evaluate the different generators with real data (four modules, $110 \mathrm{~kW}$ rated power, located in Bilbao port). These are the conclusions obtained from this study,

- The control of the converter has two independent loops, and the generator takes part only in one of them. All generator types need to implement the rotation speed and load torque as setpoint. In addition, the DFIG with $\mathrm{FC}$ is able to regulate the reactive power in the grid.

- The use of a Pelton turbine allows to work with high rotation speeds, requiring smaller and simpler generators, without gearboxes. The commercial turbine used in the example has been designed for a rated speed of 1500rpm. But if variable speed is used, the occurrence distribution is located below the rated speed (because the small waves are more repeated), so it would be advisable to displace the working pressure above, to absorbe more energy.

- The use of variable speed improves the efficiency up to $5 \%$, increasing in $10-15 \%$ the initial cost of the facility

- Due to the random nature of waves, the asynchronous generators do not suit in weak or isolated grids

Each conversion system has shown advantages and disadvantages, year by year prices are more affordable and technologies are improving. The generator must be selected for each location in collaboration with the promoter. 


\section{References}

[1] A. Lemonis, "Annual report 2006, International Energy Agency. Implementing agreement on ocean energy systems Ocean Energy systems", IEA-OES Executive Comite, Geneve, Switzerland, 2007

[2] M.J. Morris et al., "Wavenet, Results from the work of the European Thematic Network on Wave Energy, EESD, Brussels, 2003

[3] Y. Torre-Enciso, I. Ortubia, L.I. López de Aguileta and J. Marqués, "Mutriku Wave Power Plant: from the thinking out to the reality" ETWEC'09 Uppsala, Sweden 2009

[4] L. Christensen, E. Friis-Madsen and J.P. Kofoed, "The wave energy challenge. The Wave Dragon case", PowerGen'05 Europe conference, 2005

[5] M.G. de Sousa Prado, F. Gardner, M. Damen and H. Polinder, "Modelling and test results of the Archimedes wave swing", IMechE, 2006

[6] E.B. Agamloh, A.K. Wallace and A. von Jouanne, "A novel direct-drive ocean wave energy extraction concept with contact-less force transmission system, Renewable Energy, 2008, Vol. 33, pp 520-529

[7] G.M. Joselin Herberta, S. Iniyanb, E. Sreevalsanc, S. Rajapandian, "A review of wind energy technologies", Renewable and Sustainable Energy Reviews, Vienna, 2007, Vol. 11, pp. 1117-1145

[8] C. Penche, "Guide on How to Develop a Small Hydropower Plant”, ESHA, Brussels, 2004
[9] "Three phase Synchronous and Asynchronous Generators. Hydropower applications" Catalogue SIN.CT.027.1 GB, FKI-Marelli Motori, 2009

[10] "Three-phase asynchronous generators" Catalogue 03-106 E, VEM motors GmbH, 2009

[11] J. Cruz (ed.), "Ocean wave energy: current status and future prepectives", Springer Verlag, Berlin, 2008

[12] J.L. Osa and E. Zulueta, "Control strategy of the MGR Wave Energy Converter”, ICREPQ'09, Valencia, 2009

[13] "Clima medio de oleaje, Boya de Bilbao, 19902003”, Banco de datos Oceanográficos, Puertos del Estado, Cartagena, Spain 2004

[14] "Small Pelton Turbines, catalogue t2979e", Voith Siemens Hydro Power Generation GmbH, Heidenheim, Germany 2007

[15] J. Calvert, "Technical derivation of basic impulse turbine physics", http://mysite.du.edu/ jcalvert/tech/fluids/turbine.htm

[16] J.L. Osa and E. Zulueta, "Modelling of the MGR Wave Energy Converter", EWTEC'09, Uppsala, Sweden, 2009

[17] M. Taghi Ameli, S. Moslehpour and A. Mirzaie, "Feasibility Study for Replacing Asynchronous Generators with Synchronous Generators in Wind Farm Power Stations, IAJC-IJME, Seattle, USA, 2008 